\title{
A QUIXOTE MULHER - FICÇÃO E FILOSOFIA
}

\author{
Lívia Guimarães*
}

RESUMO Neste artigo, apresento uma interpretação feminista do romance The Female Quixote, de Charlotte Lennox, publicado em 1752. Em minha hipótese, Lennox responde às acusações de que romances são falsos e, por isso, repreensíveis, ao defender o gênero enquanto instrumento de crítica social e meio de transmissão e obtenção de conhecimentos das mulheres. Assim, ao mesmo tempo em que atribui valor ético, político e epistêmico a narrativas ficcionais, ela contribui também para uma reconceptualização dos conceitos de "verdadeiro" e "falso".

Palavras-chave Ficção, Filosofia, Quixote, Mulher, Lennox

ABSTRACT I present in this paper a feminist interpretation of the novel The Female Quixote, by Charlotte Lennox. In my hypothesis, Lennox meets the charge of falsity leveled against early modern novels with a defense of the genre as a tool of social critique and a medium for the achievement and transmission of women's knowledge. Thereby she promotes a revision of the concepts of "truth" and "falsity", while at the same time she endows fictional narratives with ethical, political and epistemic significance.

Keywords Fiction, Philosophy, Quixote, Female, Lennox * Professora do Departamento de Filosofia da Universidade Federal de Minas Gerais. Artigo recebido em
novembro de 2004 e aprovado em junho de 2005. livia.guimaraes@terra.com.br

KRITERION, Belo Horizonte, $n^{0}$ 111, Jun/2005, p. 104-116 
I prefer, where truth is important, to write fiction. Virginia Woolf

\section{1.}

O feminismo do início da modernidade aspirava, sobretudo, a melhores oportunidades de educação para as mulheres, esforçando-se em abrir-lhes acesso a domínios de conhecimento até então proibidos. ${ }^{1}$ Um argumento recorrente de Mary Astell a Mary Wollstonecraft é o de que, em recebendo a mesma instrução que os homens, mulheres serão capazes de desenvolver as mesmas elevadas capacidades racionais. ${ }^{2}$ Ao argumento, geralmente se seguem propostas concretas de mudança, com a formulação de projetos educacionais que determinam o que buscar e o que evitar na formação intelectual das jovens. ${ }^{3}$

Astell, em A Serious Proposal to the Ladies, recomenda que elas se dediquem a leituras sérias. Wollstonecraft vai um pouco mais longe. No $A$ Vindication of the Rights of Women, ao propor uma boa instrução, ela tem em vista a participação feminina no domínio da política e nas questões públicas, que contam entre os seus legítimos interesses. Assim, concentrando-se na questão das habilidades e dos interesses apropriados para mulheres, e batendose contra a sua exclusão, as pensadoras feministas dos séculos XVII e XVIII estão à procura do reconhecimento de sua capacidade para razão e objetividade.

Um outro tema da época foi a questão do romance. Quando surgiram no século XVII, romances eram imensamente populares entre um público leitor que se constituía, cada vez mais, por uma maioria de mulheres. Também eram mulheres as principais autoras e as protagonistas dos enredos, em que predominavam intrigas amorosas. Na primeira metade do século XVIII, o romance havia se tornado uma matéria importante de debate, objeto da atenção, e até mesmo do consenso entre mulheres e homens interessados no problema da racionalidade e da educação feminina.

Fosse porque o considerassem uma ocupação frívola, ou porque o vissem como uma ameaça à integridade moral e intelectual das leitoras, recomendavase sua substituição por literatura científica, adequada para instrução em

1 Refiro-me ao contexto de pensamento britânico, que principalmente importa para este trabalho.

2 Para uma interessante revisão deste movimento, cf. SMITH. Intellectual Bases for Feminist Analyses: The Seventeenth and Eighteenth Centuries, 1992.

3 Mesmo mantendo as tradicionais artes domésticas e sociais, tais como bordado, costura, dança e boas maneiras, acrescentam-se línguas, clássicas ou modernas e, nas propostas mais ousadas, matemática e ciência. 
conhecimentos verdadeiros e cultivo das capacidades intelectuais; ou se pedia uma reforma, que transformasse o romance em veículo de ensinamentos morais válidos. Para seus críticos, por razões diversas, romances eram ficções perigosas. Em seus argumentos, eles começavam por constatar a falsidade das narrativas, seguiam com a denúncia do seu absurdo, e concluíam condenando suas consequiências morais e epistêmicas. Como parte dessa intensa campanha, eles propunham que as narrativas ficcionais se tornassem consistentes com o conhecimento objetivo, as leis da probabilidade e os valores morais. Sua motivação, eles diziam, era proteger as mentes de jovens leitoras impressionáveis.

Se antes temia-se que leituras mais difíceis que as devocionais e sobre economia doméstica, por exigir muito esforço, pudessem provocar o adoecimento da frágil constituição feminina, agora o que se teme é que romances, enquanto fantasias irreais, provoquem o seu enlouquecimento. ${ }^{4}$

\section{2.}

Minha intenção neste artigo é examinar, sob um enfoque feminista, diante do cenário esboçado acima, o romance The Female Quixote, de Charlotte Lennox, publicado em 1752, cuja contribuição, apesar de indireta, parece-me marcante, tanto para a questão do romance, como para o tema da razão e do conhecimento das mulheres. ${ }^{5}$

Diferentemente de suas contemporâneas, Lennox não elabora uma defesa das habilidades racionais das mulheres e seu direito a participar na esfera pública. Porém, transparece em seu romance uma reflexão sobre paradigmas concorrentes para o cultivo da mente feminina. The Female Quixote é a história de uma jovem inteligente e capaz, cuja mente supostamente foi contaminada pelas noções adquiridas na leitura excessiva de romances. Lennox faz uma comédia, não um drama, da situação - um primeiro indício de suas reservas quanto à condenação exaltada dessa literatura. Às preocupações dramáticas e exageradas, ela responde com uma paródia, explorando o lado cômico do alarme em torno da questão.

Minha hipótese é que, além disso, sob o disfarce da comédia e contra as expectativas da época, o livro reconhece e defende nos romances sob ataque

4 Um exemplo do primeiro temor é o caso de Elizabeth Montagu. Conta-se que ela teve que estudar latim (considerado uma atividade de risco para uma mulher) secretamente, nas horas em que todos supunham que estivesse lendo romances inofensivos.

5 Para referência: LENNOX. The Female Quixote or The Adventures of Arabella, 1989. 
uma tradição de conhecimento representada por mulheres, onde se incluem valores, fins e modos de aquisição e transmissão próprios. Nessa intepretação, Lennox assume uma posição incomum, em vivo contraste ao pensamento predominante. Incerta sobre se efetivamente é do interesse das mulheres tornar também seus os modos e conceitos de autoria masculina, ela levanta a suspeita de que a razão e objetividade a que autoras como, por exemplo, Astell aspiram, podem estar contaminadas por uma perspectiva androcêntrica.

Aí reside seu interesse filosófico e sua atualidade. ${ }^{6}$ Possivelmente, Lennox se reconheceria próxima de uma parte significativa do pensamento feminista recente, que se empenha em resgatar modos de conhecer desenvolvidos independentemente por mulheres, que não toma os conceitos modernos de razão e conhecimento automaticamente por princípios universais, e que se pergunta: são satisfatórias as propostas modernas para o conhecimento? Elas são desejáveis? Se não, então que usos de suas mentes, que métodos e valores mulheres devem praticar?

Lennox ensaia uma resposta, ao enfatizar, pela análise da influência de romances sobre sua Quixote, o uso da imaginação, o papel de histórias, narrativas, valores e paixões, e o envolvimento coletivo e próximo na obtenção de conhecimento. Nos romances, ela encontra algo válido que falta ao programa moderno, que se pretende autônomo e imparcial - ou, numa palavra, masculino. Implicitamente, ela sugere que não é preciso substituir os romances, nem reformá-los segundo as exigências daquele programa. Ao apresentar esta interpretação de Lennox, espero compreender também uma das maneiras como mulheres podem se relacionar a seus próprios saberes e aos desafios colocados pelos saberes dos homens.

\section{3.}

Mas vejamos o livro. Arabella é a "Quixote Mulher". Órfã de mãe e educada numa propriedade rural, distante da corte, sua primeira exposição à cena

6 Como sabemos, críticas feministas afins às de Lennox só se tornaram possíveis bem mais tarde, e só depois de sofrermos uma disciplina de pensamento que nos nega nossos corpos e nos aliena de nossas experiências. Algumas das referências recentes incluem, por exemplo: Geneviéve Lloyd que, no The Man of Reason - Male and Female in Western Philosophy, mostra o conceito moderno de razão sendo codificado, simbólica e metaforicamente, dentro do gênero masculino; Susan Bordo que, no The Flight to Objectivity, mostra a arquitetura da epistemologia moderna separando-se do universo feminino, ao abrir mão de simpatia e intersubjetividade em proveito de conceitos como os de individualismo e autonomia, relacionados ao universo masculino; Caroline Merchant que, no The Death of Nature, mostra dominação de gênero na substituição, pela ciência moderna, do modelo orgânico pelo mecânico de conhecimento. Diferenças à parte, essas autoras identificam um profundo recorte de gênero atravessando todo o pensamento moderno. 
mundana acontece pouco antes da morte do pai. Apesar de órfã, Arabella não fica desamparada; ela é rica, senhora de sua fortuna. E tem opiniões próprias, que expressa sem acanhamento nem medo, em discursos bem articulados. Agência e assertividade são características que imediatamente a distinguem.

Mas Arabella tem um outro diferencial. Seu mundo - e a história da "Quixote Mulher" começa aqui - é o de seus livros, e os livros são romances. Ao se casar, a mãe, prevendo o isolamento e solidão futuros, levou consigo para o campo, como parte do enxoval, uma coleção de romances franceses (por Madeleine de Scudéry) - histórias de heroísmo e paixão ardente, sobre as vidas ficcionais de rainhas da Antigüidade. Neles, as heroínas têm aventuras tumultuadas: seus amantes passam pelas mais difíceis provas de coragem e devoção antes de conquistarem o direito a lhes declarar seu amor; os vilões, por sua vez, incansavelmente as perseguem e ameaçam com tentativas de rapto, estupro e aprisionamento. Nesses livros, os grandes acontecimentos históricos não são senão uma parte das complicadas tramas de amor em torno das heroínas, tramas onde os heróis precisam aprender a lhes dedicar respeito e obediência. A história antiga se desdobra em amores de mulheres - Cleópatra, Statira, Júlia, Clelia, entre várias outras.

Os romances franceses, que fizeram parte do dote da mãe, tornaram-se, com a morte precoce, seu único legado para a filha. Após o falecimento da mãe, os livros são levados para a biblioteca do castelo. Sem a tutela do pai, que não se interessa por eles, Arabella não apenas os lê avidamente, mas também os toma por narrativas de história verdadeira. Ela emula as heroínas, cultiva altos ideais românticos e elevadas aspirações a honra e glória. No comportamento dos homens, enxerga indícios de paixão, ora do herói, ora do vilão. Assim como o Quixote de Cervantes, a Quixote Mulher parece enlouquecida pelos romances. Sua grande aventura virá no teste das crenças adquiridas por meio deles, contra a realidade das crenças de quase todos à sua volta.

\section{4.}

As aventuras de Arabella materializam a controvérsia em torno do romance. Nesse sentido, The Female Quixote é um texto metaficcional. Nas próximas seções, pretendo mostrar como ele é também um texto protofeminista. Em primeiro lugar, porque Lennox se refere, por meio de Arabella, a autoras e leitoras, defendendo-se ao defender o romance. Nesse mesmo espírito de resistência, ela se recusa a fazer de sua heroína uma mártir, jamais colocando Arabella em situações onde ela só tenha a perder. Arabella não vive em constante 
pesar, e não sofre mais do que o necessário. ${ }^{7}$ Ao contrário, com frequiência, suas aventuras têm final feliz. Já nesse sentido, a moral da história é que romances não são a perdição das jovens; eles podem, inclusive, oferecer modelos de emancipação.

Uma obra de ficção, A Quixote Mulher reinstitui precisamente o espaço negado pelos críticos. Ao exaltar este espaço diferenciado, Lennox também suscita o questionamento da legitimidade da disputa em torno dele. Ela sabe que são muitas as posições sobre o romance. Unificá-las constituiria um subterfúgio. Não se pode simplesmente dizer que romances contam histórias falsas e que, por isso, são condenáveis. O que então podem os críticos querer dizer quando os condenam por sua falsidade, absurdo e desobediência às leis da probabilidade? O que verdadeiramente se passa nos romances? O que deveria ser reconhecido por quem os examina de perto?

Lennox mostra que romances são um espaço que pertence e é habitado por mulheres. Arabella, a leitora prototípica, é filha de uma tradição e de uma linhagem que se estende desde as heroínas da Antigüidade, passando por Madeleine de Scudéry, pela mãe, por Arabella, pela própria Lennox, até chegar a nós, suas leitoras mais recentes. Arabella dá continuidade à tradição: ela se interessa pelas aventuras de todas as mulheres que encontra, procura ouvi-las e manter sua memória. É nesse repertório de experiências que ela busca conhecimento e instrução sobre como se conduzir na vida.

Nessa linhagem, a transição entre os elos ficcionais e não ficcionais é contínua. Escritoras e suas personagens, reais e imaginadas, todas igualmente constituem um mundo comum, cuja cultura se transmite de umas às outras por várias gerações. A linha de transmissão, vivida, escrita e imaginada, passa ao largo dos homens, inteiramente despercebida por eles. O pai de Arabella não lê romances. Sir George, o impostor e vilão da história, os lê, mas não os compreende. Quando tenta se fazer passar por um herói romântico, ele comete erros fatais: relata um passado de inconstância no amor, enquanto, no presente, presta obediência menos que perfeita aos comandos de Arabella. A Glanville, o herói, os romances simplesmente deixam perplexo. Glanville ama Arabella com sinceridade, mas a despeito da influência dos romances sobre ela; de fato, ele impõe-se a missão de curá-la dessa influência.

No que entendo ser uma denúncia, os personagens masculinos ficcionais se comparam aos reais críticos, contestando o valor e a verdade dos romances.

7 Heroínas dos romances reformados, ao contrário, sofrem cruelmente e são verdadeiras mártires, dispostas a tudo - e tudo aqui significa os maiores sacrifícios, incluindo a própria vida - para atingirem seus fins, que são total obediência às "virtudes femininas" da castidade, piedade e modéstia. Clarissa, de Richardson, é o exemplo óbvio. 
Para todos eles, que os desconhecem, romances fazem um mundo diferente do ordinário e, por isso mesmo, falso e ilusório. Mas, se são ignorantes, suas acusações são injustificadas. ${ }^{8}$ E sua pretensão a autoridade legisladora é ilegítima, pois os textos estão numa tradição, que não apenas lhes é estranha, mas também que não se pode simplesmente decretar fora de existência. O que os críticos sabem, afinal? Ou, talvez, o que Arabella sabe, mas eles desconhecem?

\section{5.}

Em The Female Quixote, Lennox não se limita a manter sentinela nas fronteiras do romance. Ela se apóia numa posição epistemológica interessante, a qual nem os críticos melhor intencionados chegaram a considerar. Três fatores sobressaem no livro, o primeiro deles relacionado a métodos e valores - quem conhece, como e para que. Ao procurar conhecimento, Arabella é guiada primariamente por um interesse humano. Ela se interessa pela busca da felicidade, pelo cultivo das virtudes e pela realização de ideais. O que motiva a sua curiosidade é o bem viver. Além disso, ela não procura respostas através de uma análise neutra e distanciada mas, ao contrário, no envolvimento próximo com as pessoas que quer compreender e com quem espera aprender. Finalmente, relatando, aconselhando ou alertando, Arabella compartilha cooperativamente suas experiências e descobertas.

Reunidas, essas características delineiam um modelo que pode, talvez vantajosamente, ser comparado a outros possíveis para o conhecimento. Conhecer pode constituir-se tanto em algo como participar do julgamento em um tribunal, quanto, alternativamente, participar de uma história. Esta última é a alternativa que Lennox ilustra. Antes de perguntar pelas credenciais de verdade das narrativas, ela nos leva a reconhecer, nos romances, modelos, possivelmente aptos, de atividade cognitiva.

Além disso, a questão sobre a falsidade dos conteúdos dos romances não é simples, embora pareça sê-lo. Nesse debate, os sentidos de "falso" e "verdadeiro" são múltiplos, díspares, e vão muito além do fato óbvio de que, inegavelmente, se considerados estritamente enquanto conteúdos fáticos, romances são falsos.

8 É curioso observar que este estado de ignorância se aplica até mesmo aos homens próximos de Lennox, que era parte do círculo do Dr. Johnson e Richardson, e recebeu encorajamento de amboss durante a criação do livro. Richardson leu e comentou o rascunho, o Dr. Johnson inclusive escreveu a dedicatória. Para eles, certamente The Female Quixote acabava no seu sentido mais imediato: o de uma sátira aos romances. 
Os críticos do romance, advertida ou inadvertidamente, equiparavam a ficção que não reforçasse a moral vigente ao falso e corrupto, assimilando esses termos numa, à primeira vista, estranha equivocação. Todo o peso retórico do seu discurso repousava na denúncia, não qualificada, de falsidade. Ao igualarem o fictício e o moralmente errado, eles concentravam seus argumentos na primeira metade da equação, tomando a segunda metade como conseqüência natural. É como se estivessem dizendo: é ficcional, portanto é falso, portanto é imoral. Tais críticos distinguiam ainda ficções aceitáveis das inaceitáveis, recomendando que os romances se alinhassem às crenças, valores e desejos que queriam ver promovidos, mas que, com o auxílio de equivocação, eles podiam apresentar como universalmente verdadeiros.

Já as autoras criticadas muito provavelment diriam ser, em um sentido importante, verdadeiro aquilo mesmo que os críticos diziam ser falso. Suas narrativas continham uma verdade possível, entendida ora como uma projeção para o futuro ou retorno ao passado, ora como o desenho de uma situação atual, apesar de não explicitamente reconhecida por todos - ambas possibilidades que os críticos não se dispunham a admitir. Explicando-me melhor: nos romances do século XVII e início do XVIII, cada autora, à sua maneira, descrevia as relações entre homens e mulheres e, nos meandros das tramas com final feliz, encontrava, muitas vezes, um meio de crítica social, reflexão, e proposta de mudança. ${ }^{9}$ Romances eram experimentos em liberdade de ação e expressão, retratando situações de particular interesse para as mulheres, apresentando soluções novas, e insistente afirmação do seu direito à busca por felicidade. ${ }^{10}$

9 Acredito que a ênfase em suas qualidades críticas e experimentais pode salvar o romance do início da modernidade de objeções como as levantadas por Hilan Bensusan no artigo "Felicidade ou glória? — As tramas que orientam a vida e a vida para além das tramas", apresentado no encontro sobre Filosofia e Ficção, em 2002, na Universidade Federal de Ouro Preto. Bensusan argumenta por uma literatura sem honra, glória e finais felizes, que seja solidária às personagens - ao não fechá-las nos enredos das tramas - e às leitoras - ao não lhes impor ideais, sentido e expectativas estranhas às suas próprias vidas.

10 Alguns exemplos ilustrativos: nos livros de Eliza Haywood, assim como nos de Aphra Behn, é comum as personagens fazerem um experimento na conquista de autonomia. A fim de viverem as vidas de sua escolha, elas muitas vezes adotam as maneiras e comportamentos dos homens, que vão desde o se vestirem em trajes masculinos, até o se envolverem em conflitos políticos, sem escrúpulos em mentir e trapacear, quando necessário. Gender-bending é sua tática político-sexual, algo que, como mostram as autoras, mulheres podem praticar com sucesso. Haywood e Behn, além de elevarem as protagonistas acima das convenções sociais, destituem os homens de tudo o que eles pretendem Ihes pertencer exclusivamente. Frances Burney faz, em sua obra, o experimento de outras políticas. Diante das mesmas dificuldades que as anteriores, suas personagens recorrem a medidas que são tão mais reflexivas quanto são mais laboriosas. Progredindo lenta e firmemente, contra guardiões desonestos e cláusulas testamentárias restritivas, elas terminam por realizar seus destinos, ainda que a um alto custo: somente porque são mulheres, elas são roubadas de suas riquezas e coagidas à obediência. Em circunstâncias adversas, elas precisam das armas da resistência e da força de suas convicções para afirmarem seu valor e direito de escolha. Entre Haywood e Behn de um lado, e Burney do outro, há um intervalo que talvez ajude a explicar a passagem do exercício relativamente anárquico das primeiras ao comprometimento sério da última. Foi nesse intervalo que o romance sofreu as maiores críticas. 
Assim, embora travestida nos termos do verdadeiro e falso, provável e improvável, real e irreal, parece-me claro que componentes de gênero são o que de fato explica a controvérsia. ${ }^{11}$ Nessa hipótese, quando ao romance importa a distinção entre verdadeiro e falso, onde o falso representa uma ameaça social, estamos assistindo antes ao conflito onde homens procuram, sob o disfarce da íntegra verdade, exercer controle e domínio sobre mulheres que utilizam esta escrita para dar voz a crenças, métodos, e valores próprios. ${ }^{12}$

\section{6.}

Críticos e autoras parecem se contradizer mutuamente na questão, aparentemente simples, do valor de verdade dos romances. Suas contradições indicam o caráter social da disputa, revelam a existência de pontos de vista e mostram que os conceitos do verdadeiro e falso não são facilmente objeto de consenso, e que, menos ainda, eles são absolutizáveis. Abordar a questão do romance pede uma teoria onde não apenas as leitoras, mas todos sejam considerados intérpretes interessados, e onde se supere a pretensa simplicidade, enganosa até no caso dos conceitos mais básicos.

Daí vem o segundo fator significativo do The Female Quixote. Lennox é, no século XVIII, coerentista e anti-realista em epistemologia. Ela retrata em Arabella uma intérprete operando dentro de um sistema coerente de crenças e julgando as pessoas com quem se relaciona a partir de como se posicionam dentro desse sistema. Até que ponto elas obedecem às Leis do Romance ${ }^{13}$ Arabella detecta sua conformidade ou não-conformidade pela consistência ou inconsistência do comportamento observado.

11 Uma abordagem instigante para o problema da verdade me foi sugerida por Virgínia de Araújo Figueiredo, em comunicação pessoal. Embora este artigo não consiga alcançar a radicalidade de sua intuição, considero-a inteiramente correta. Ela diz: "Num projeto radical, a história da verdade deveria ser reescrita a partir do ponto de vista de uma luta entre os sexos. Por que não? Marx não propôs que o desenvolvimento da história social e política fosse pensado a partir da luta de classes? Não consistiria nisso a apropriação filosófica da contribuição freudiana? Talvez a verdade não passe de uma metáfora espiritualizada para tentar neutralizar o poder e a força irresistível das mulheres. Jeanne-Marie Gagnebin propôs sugestivamente que os filósofos nunca fizeram outra coisa além de pensar sobre mulheres, já que a natureza, tema recorrente e que atravessa a história da filosofia como um todo, nada mais seria senão uma metáfora que substituiu o feminino."

12 Com efeito, o sucesso da crítica coincide - não coincidentemente - com o estabelecimento de um novo cânone do qual as autoras anteriores são sumariamente excluídas. Esse cânone tem em Richardson o primeiro luminar.

13 As Leis do Romance são as leis do amor romântico. Supremas, essas leis estão acima de todas as demais. Elas determinam a glória como fim último: a glória do herói, em respeitar e servir corajosa e obedientemente sua amada, e a da heroína, em impor ao amante dedicação obediente e virtuosa. No romance, honra e virtude estão sempre relacionadas aos afetos e ao valor das mulheres. 
Mas, tanto quanto a coerência, importam para Lennox os efeitos das crenças, ou seja, crenças verdadeiras dependem de consequiências - são as que permitem ação, escolha e decisão. Lennox adianta esse critério pragmático ao contar os sucessos de Arabella como intérprete. Ela comete quase tantos erros quanto acertos nas suas interpretações. Além disso, freqüentemente seus acertos vêm ao termo de uma série de erros intermediários, atravessando um caminho de engano e ilusão. Considerados os elementos imponderáveis no processo, o que realmente importa é se as crenças, em conjunto, possibilitam que caráter e conduta sejam consistentemente interpretados, e se as interpretações têm conseqüências pragmáticas bem-sucedidas.

$\mathrm{O}$ conjunto de crenças de Arabella passa no teste. Ele não é totalmente coerente, mas o suficiente para fazer sentido do que lhe acontece e, o que é mais notável, conduzir-se com sucesso em todas as situações que verdadeiramente importam, e quase todas as de menor importância. Arabella alcança insight psicológico sobre caráter e motivações. Ela é bem-sucedida ao discriminar entre pretendentes valorosos e vis (Glanville e Sir George), homens verdadeira e pretensamente eruditos (o Doutor e Mr. Selvin), mulheres sábias (a Condessa), levianas (Miss Glanville, sua prima), dignas de confiança (sua acompanhante, Lucy). Isso favorece sua conduta, permitindo-lhe boas escolhas e respostas apropriadas.

O que mais se pode esperar das crenças? Lennox parece responder: mais nada, quando esboça uma visão coerentista, em que o principal critério está nas conseqüências práticas das crenças. Assim ela também torna possível a oposição à epistemologia totalitária e exclusivista dos críticos do romance. Mais interessada em crenças como produtos culturais e meios de ação do que como cópias de evidências, Lennox questiona a teoria de representações privilegiadas dos oponentes.

\section{7.}

Mas há ainda um terceiro e último fator a se enfatizar: o Quixote Mulher acaba na conversão de Arabella. Como isso acontece? A revisão das crenças acontece apenas no momento em que agir segundo elas a levaria a colocar em risco sua própria vida e vidas alheias. Seu conjunto de crenças passa por três testes. Um deles é o próprio desenrolar dos acontecimentos: Arabella quase morre afogada ao se atirar no rio Thames, seguindo o exemplo de Clelia (uma das personagens de Scudéry), ao tentar escapar de perseguidores imaginários. 
Os outros testes são dois diálogos, o primeiro deles uma conversa com a Condessa, e o segundo uma discussão com o Doutor em teologia. ${ }^{14}$

A Condessa é uma mulher madura, com fama de grande virtude. Quando jovem, também havia estado sob a influência de romances. Ela e Arabella usam o mesmo código, e ambas concordam sobre a excelência dos seus ideais. Na conversa, o principal ponto da Condessa é mostrar que, nos dias atuais e numa cultura cristã, a obediência estrita às leis do romance é considerada viciosa, além de proibida por lei. Em suas palavras: "O costume altera a própria natureza das coisas" (Lennox, 1989, p. 328). ${ }^{15}$ Por exemplo, hoje, ela diz, um amante não pode mais combater em duelo o seu adversário. Se o fizer, ele será punido e sua ação, considerada injusta. Ademais, hoje, o mérito de uma mulher está em uma existência doméstica e casta, não mais em extraordinárias aventuras amorosas, que podem até mesmo prejudicar sua reputação. A Condessa usa a relatividade dos valores e costumes para sensibilizar Arabella a outros pontos de vista. Tendo se resignado a viver em conformidade com as convenções atuais, sua mensagem para Arabella é ambígua: a Condessa possui a virtude moderna, mas faltaram-lhe aventuras, paixões, mobilidade. A conversa é, portanto, inconclusiva.

No segundo diálogo, o Doutor prefere fazer um desafio a Arabella, escolhendo as armas da evidência e probabilidade. Esse diálogo personifica a controvérsia sobre o romance: Arabella, a Quixote mulher, fala pelas autoras e leitoras, enfrentando os críticos, representados pelo Doutor, personagem que não tem nome, e que assume o título de autoridade teológica e poder patriarcal.

Em muitos sentidos, Arabella vence. Ela demonstra competência impecável, tanto no uso dos argumentos, como na escolha dos termos do debate. É ela quem distingue os pontos a serem decididos, a saber, se romances são: (1) ficções (2) absurdas e (3) criminosas. Também ela é quem determina a ordem de importância desses pontos, transferindo para (2) e (3) a ênfase inicialmente colocada pelo Doutor em (1).

Com o discernimento de uma debatedora sofisticada e generosa, Arabella concede ao Doutor o item (1), mesmo sabendo que, como tudo que depende do testemunho e experiência humanos, ele é indecidível de maneira absoluta, e também sabendo que temos somente, sempre, versões da história. Sobre o item (2), ela argumenta que, embora sejam ficções, os romances podem não

14 Lennox escreveu a conclusão do livro sob a tutoria de Dr. Johnson. Para alguns, a hipótese de que a conclusão tenha sido escrita pelo próprio Dr. Johnson soa plausível. A voz do Doutor é, muito claramente, sua, inclusive porque Ihe parodia o estilo e reproduz as idéias.

15 "Custom changes the very Nature of Things." 
ser absurdos, se tomados enquanto "cópias da vida" e "modelos de conduta". Isso a leva, e ao Doutor, ao terceiro e mais importante item, acerca do valor moral dos romances. Nesse momento, ele argumenta que romances são condenáveis, pois eles tendem a:

[A]vivar a Chama das Paixões do Amor e Vingança; duas Paixões que, mesmo sem esses poderosos Auxilares, têm, em sua supressão, um dos mais árduos trabalhos da Razão e da Piedade, mas que, contudo, precisam ser suprimidas, se temos Esperança de aprovação aos Olhos do único Ser, cuja aprovação pode nos tornar felizes. ${ }^{16}$ (Lennox, 1989, p. 380)

Arabella não responde nem à condenação da paixão do amor, nem ao apelo à aprovação divina. Ela cora, mas não diz uma palavra sequer. O Doutor interpreta sua reação como sinal de vergonha e embaraço. Mas ela pode significar outras coisas, inclusive total desacordo, silenciosamente eloqüente. Já as implicações éticas decorrentes do fato de que os princípios de honra propiciam derramamento de sangue conseguem sensibilizar e, subitamente, converter Arabella. Aqui, o Doutor vence.

Mesmo assim, penso que permanece um resíduo subversivo na conclusão. Apesar de abandonar sua crença nos romances, Arabella não a abandona senão seguindo os preceitos, que ela não abandona, do próprio romance: ela não se rende aos ataques contra a paixão do amor. Rende-se apenas quando passa a ver nos romances uma oposição a algo que lhe é igualmente caro, a vida. Suas crenças e a revisão delas se mostram permeáveis a valores e sentimentos, e, por isso, Arabella continua, até na conversão, fiel às diretrizes mais fundamentais de seu modelo inicial. Em um sentido importante, ela continua acreditando nos romances.

\section{8.}

Lennox mostra em sua ficção como mulheres, por seus próprios meios e em um ambiente seu, realizam uma atividade de conhecimento. Ela faz do enredo de The Female Quixote uma amostra de modos de funcionar cognitivos, cujos resultados ela prova serem válidos segundo critérios de adequação e obediência a valores que, dois séculos mais tarde, feministas virão trazer para o espaço, até então negado a elas, da discussão acadêmica.

16 "[G]ive new Fire to the Passions of Revenge and Love; two Passions which, even without such powerful Auxiliaries, it is one of the severest Labours of Reason and Piety to suppress, and which yet must be suppressed if we hope to be approved in the Sight of the only Being where Approbation can make us happy." 
Ao mesmo tempo, The Female Quixote expõe as restrições sexistas que tentam exercer controle sobre estas mulheres, por meio de juízos negativos acerca de mundos ficcionais. Ao explicitar um recorte de gênero até então mantido implícito no debate sobre o romance, Lennox também redesenha o mapa epistêmico e redefine, ao incluir essa variável, os termos em que se faz a determinação das crenças verdadeiras.

"A Quixote Mulher" contribuiu para o debate moderno sobre a razão das mulheres. Uma obra de ficção perceptiva e filosófica, ela pode, ainda hoje, suscitar o debate sobre conhecimento cooperativo, imaginativo, e interessado. ${ }^{17}$

\section{Referências}

BENSUSAN, Hilan. Felicidade ou glória? - As tramas que orientam a vida e a vida para além das tramas. In: ENCONTRO "FILOSOFIA E FICÇÃO", Universidade Federal de Ouro Preto, 2002, organização de Imaculada Kangussu. (Mimeografado) LENNOX, Charlotte. The Female Quixote or The Adventures of Arabella. Ed. Margaret Dalziel. Oxford/New York: Oxford University Press, 1989.

SMITH, Hilda L. Intellectual Bases for Feminist Analyses: The Seventeenth and Eighteenth Centuries. In: HARVEY, Elizabeth D.; OKRUHLIK, Kathleen. (Ed.). Women and Reason. Ann Arbor: University of Michigan Press, 1992.

17 Pelos valiosos comentários, críticas e sugestões, muito obrigada ao Grupo PET-Filosofia, à linha de pesquisa em Lógica e Filosofia da Ciência da UFMG, a Imaculada Kangussu e participantes do encontro "Filosofia e Ficção" e a Virgínia de Araújo Figueiredo. 